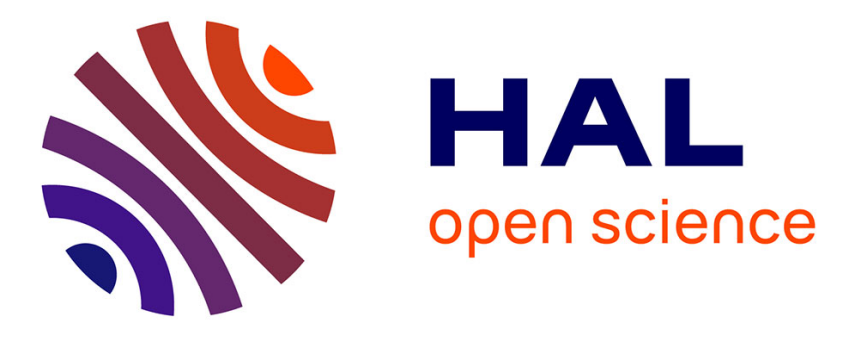

\title{
Novel Ge-Ga-Te-CsBr Glass System with Ultrahigh Resolvability of Halide
}

Ci Cheng, Xunsi Wang, Tiefeng Xu, Qingde Zhu, Lihong Sun, Zhanghao Pan, Qiuhua Nie, Peiqing Zhang, Yuehao Wu, Shixun Dai, et al.

\section{To cite this version:}

Ci Cheng, Xunsi Wang, Tiefeng Xu, Qingde Zhu, Lihong Sun, et al.. Novel Ge-Ga-Te-CsBr Glass System with Ultrahigh Resolvability of Halide. Spectrochimica Acta Part A: Molecular and Biomolecular Spectroscopy [1994-..], 2015, 150, pp.737-741. 10.1016/j.saa.2015.06.029 . hal-01165429

HAL Id: hal-01165429

https://hal-univ-rennes1.archives-ouvertes.fr/hal-01165429

Submitted on 15 Sep 2015

HAL is a multi-disciplinary open access archive for the deposit and dissemination of scientific research documents, whether they are published or not. The documents may come from teaching and research institutions in France or abroad, or from public or private research centers.
L'archive ouverte pluridisciplinaire HAL, est destinée au dépôt et à la diffusion de documents scientifiques de niveau recherche, publiés ou non, émanant des établissements d'enseignement et de recherche français ou étrangers, des laboratoires publics ou privés. 


\title{
Novel Ge-Ga-Te-CsBr Glass System with Ultrahigh Resolvability of Halide
}

Ci Cheng ${ }^{1}$, Xunsi Wang ${ }^{1 *}$, Tiefeng Xu ${ }^{1}$, Qingde Zhu ${ }^{1}$, Lihong Sun ${ }^{1}$, Zhanghao Pan ${ }^{1}$, Qiuhua Nie ${ }^{1}$, Peiqing Zhang ${ }^{1}$, Yuehao $\mathrm{Wu}^{1}$, Shixun Dai ${ }^{1}$, Xiang Shen ${ }^{1}$, Xianghua Zhang ${ }^{2}$

${ }^{1}{ }^{1}$ Laboratory of Infrared Material and Devices, The Research Institute of Advanced Technologies, Ningbo University, Ningbo, Zhejiang 315211, China)

('. Laboratory of Glasses and Ceramics, UMR 6226 CNRS-University of Rennes 1, Rennes Cedex 135042, France)

\begin{abstract}
CO}_{2}$ molecule, one of the main molecules to create new life, should be probed accurately to detect the existence of life in exoplanets. The primary signature of $\mathrm{CO}_{2}$ molecule is approximately 15 $\mu \mathrm{m}$, and traditional S- and Se-based glass fibers are unsuitable. Thus, Te-based glass is the only ideal candidate glass for far-infrared detection. However, Te-based glass crystalizes easily, and its optical band gap is usually less than $0.6 \mathrm{eV}$. In this study, a new kind of Te-based chalcohalide glass system was discovered with relatively stable and large optical band gap. A traditional melt-quenching method was adopted to prepare a series of $\left(\mathrm{Ge}_{15} \mathrm{Ga}_{10} \mathrm{Te}_{75}\right)_{100-\mathrm{x}}(\mathrm{CsBr})_{\mathrm{x}}$ chalcogenide glass samples. The glass-forming ability and optical properties of these samples were analyzed by X-ray diffraction, differential scanning calorimetry, Fourier transform infrared spectroscopy, visible near-infrared spectroscopy, and Raman spectroscopy. Experiment results indicate that the glass-forming ability and thermal properties of glass samples were improved when $\mathrm{CsBr}$ was added in the host of $\mathrm{Ge}-\mathrm{Ga}-\mathrm{Te}$ glass. Ge-Ga-Te glass could remarkably dissolve $\mathrm{CsBr}$ content as much as 85 at.\%, which is the highest halide content in all reports for Te-based chalcohalide glasses. Moreover, $\Delta \mathrm{T}$ values of these glass samples were all above $100{ }^{\circ} \mathrm{C}$. The glass sample $\left(\mathrm{Ge}_{15} \mathrm{Ga}_{10} \mathrm{Te}_{75}\right)_{65}(\mathrm{CsBr})_{35}$ with $\Delta \mathrm{T}$ of $119{ }^{\circ} \mathrm{C}$ was the largest, which was $7{ }^{\circ} \mathrm{C}$ larger than that of $\mathrm{Ge}_{15} \mathrm{Ga}_{10} \mathrm{Te}_{75}$ host glass. The infrared transmission spectra of these glasses show that the far-infrared cut-off wavelengths of $\left(\mathrm{Ge}_{15} \mathrm{Ga}_{10} \mathrm{Te}_{75}\right)_{100-\mathrm{x}}(\mathrm{CsBr})_{\mathrm{x}}$ chalcogenide glasses were all beyond $25 \mu \mathrm{m}$. In conclusion, $\left(\mathrm{Ge}_{15} \mathrm{Ga}_{10} \mathrm{Te}_{75}\right)_{100-\mathrm{x}}(\mathrm{CsBr})_{\mathrm{x}}$ chalcogenide glasses are potential materials for far-infrared optical application.
\end{abstract}

Keywords: Te-based chalcohalide glass; infrared transmission spectra; glass-forming ability; optical properties

\section{Introduction}

In recent years, chalcogenide glasses have attracted increasing attention in infrared technology fields, particularly in high nonlinearity, infrared fingerprints, and life detection [1-3]. Among these projects, the Darwin Mission and the Terrestrial Planet Finder conducted by the European Space Agency and the National Aeronautics and Space Administration, respectively, are the most impressive $[3,4]$. These projects aim to demonstrate whether life exists in exoplanet. $\mathrm{H}_{2} \mathrm{O}$, $\mathrm{CO}_{2}$, and $\mathrm{O}_{3}$ are the three main molecules to create new life. Detecting these molecules needs IR optical devices with excellent infrared transparency. The infrared cut-off wavelengths of S- and Se-based glass fibers are only up to 8 and $10 \mu \mathrm{m}$, respectively. However, the main signature of $\mathrm{CO}_{2}$ molecule is approximately $15 \mu \mathrm{m}$ [5]. Hence, current infrared transparencies of these glasses

\footnotetext{
* Corresponding author. Fax: +86 57487600947.

E-mail address: xunsiwang@siom.ac.cn (X.Wang).
} 
are not sufficiently wide to match with $\mathrm{CO}_{2}$ molecular signature at $15 \mu \mathrm{m}$. Thus, a glass with wider infrared transparency is necessary. According to phonon vibration spectrum analysis [6], heavy atoms are needed for long cut-off wavelength. Te-based glasses have wider infrared transparency and longer cut-off wavelength than S- and Se-based glasses because the atom mass of Te-based glasses is larger than those of the other two glasses. In addition, the cut-off wavelength of Te-based glass in the long wavelength area is above $20 \mu \mathrm{m}$. Given the wide optical windows and low loss in 6-20 $\mu \mathrm{m}$ range, Te-based chalcogenide glasses are suitable material for far-infrared application, particularly in some gas detections, such as the greenhouse gas $\mathrm{CO}_{2}$ with absorption peaks at 4.3 and $15 \mu \mathrm{m}[7,8]$ and poisonous gas benzene with absorption peak at 14.8 $\mu \mathrm{m}[9]$. However, these glasses possess many disadvantages. First, Te cannot form stable glass alone because of its strong metallic property. Second, traditional $\mathrm{Te}-\mathrm{X}(\mathrm{F}, \mathrm{Cl}, \mathrm{Br}, \mathrm{I})$ glasses have low transition temperature; most of these glasses cannot reach more than $100{ }^{\circ} \mathrm{C}$. Its low optical band gap also limits its transmission in near IR $(<2 \mu \mathrm{m})$, which is currently well developed. Moreover, the interstructure of traditional Te-based glasses possesses numerous inherent glass network defects, and these defects can result in high intrinsic loss. To solve these limitations, many scientists have exerted effort to develop suitable Te-based chalcogenide glasses. Adon et al. [10] reported that Ge-As-Te glasses have stable structure and good formability. However, As is poisonous to the environment and has a low band gap. Wilhelm et al. [3] demonstrated that Ge-Te-I glasses possess a wide infrared transparency window and its cut-off wavelength is more than $25 \mu \mathrm{m}$. However, this glass is prone to volatilization because I element is contained. Danto et al. [5] proposed that the $\mathrm{GeTe}_{4}$ binary glass system doping $\mathrm{Ga}$ can open the $\mathrm{GeTe}_{4}$ tetrahedral network structure and split the Te-Te chains; $\mathrm{Ge}_{15} \mathrm{Ga}_{10} \mathrm{Te}_{75}$ is also superior among these glasses. Wang et al. discovered that doping halide to Te-based glass can decrease optical loss of glass $[11,12]$. The highest content of halide in the Te-based glasses is limited to 30 at.\%.

In this study, an extensive investigation was developed to study the effect of alkali-halide on $\mathrm{Ge}-\mathrm{Ga}-\mathrm{Te}$ host glass. High content of $\mathrm{CsBr}$ was added to the $\mathrm{Ge}-\mathrm{Ga}-\mathrm{Te}$ glass system to enlarge the formation of Te-based glass. The optical and thermal properties of this glass were then analyzed by Fourier transform infrared spectroscopy (FTIR) and spectrophotometry. To date, no reports exist about the influence of $\mathrm{CsBr}$ on the structure and chemical or physical properties of $\mathrm{Ge}-\mathrm{Ga}-\mathrm{Te}-\mathrm{CsBr}$ glasses.

\section{Materials and Methods}

$\left(\mathrm{Ge}_{15} \mathrm{Ga}_{10} \mathrm{Te}_{75}\right)_{100-\mathrm{x}}(\mathrm{CsBr})_{\mathrm{x}}$ glass samples were prepared by conventional melt-quenching methods. The specific glass compositions are listed in Table 1. High purities of $99.999 \% \mathrm{Ge}$, 99.999\% Ga, 99.999\% Te, and 99.999\% CsBr were selected as raw materials. The weighed raw materials were mixed into a quartz tube, which was prewashed with deionized water. The tubes were then sealed with oxy-acetylene flame under a pressure of $1 \times 10^{-3} \mathrm{~Pa}$ and heated in rocking furnaces with specific heating curve. Afterward, the quartz tubes were quenched in ice water and then annealed at $10{ }^{\circ} \mathrm{C}$ below $\mathrm{Tg}$ in a prepared furnace. The glass rods were removed and cut into discs. A polishing procedure on the discs is indispensable to test the properties of these glasses precisely.

The Archimedes' principle was used to measure the density of glass samples (with an accuracy of $\pm 0.001 \mathrm{~g} / \mathrm{cm}^{3}$ ). XRD diffraction patterns of glass samples were tested through German Bruker D2 X-ray diffraction apparatus. Vis-near-infrared spectra of glass samples were acquired 
using a Perkin-Elmer Lambda 950 spectrophotometer in the range of 400-2500 nm. The infrared transmission spectra were obtained with Nicolet 380 FTIR in a spectral range of $400-4000 \mathrm{~cm}^{-1}$. Glass transition temperature ( $\mathrm{Tg}$ ) and onset crystallization temperature ( $\mathrm{Tx})$ were determined with differential scanning calorimetry (DSC) measurements at 50 and $350{ }^{\circ} \mathrm{C}$ with a heating rate of 10 ${ }^{\circ} \mathrm{C} / \mathrm{min}$ via a TAQ2000 thermal analyzer. Raman spectra of glass samples were gathered in the range of $80 \mathrm{~cm}^{-1}-800 \mathrm{~cm}^{-1}$ by using a Renishaw Raman microscope with an Ar+ ion laser that operates at a wavelength of $488 \mathrm{~nm}$. The spectral resolution was set to $1 \mathrm{~cm}^{-1}$. All of these optical tests were performed at room temperature.

\section{Results and Discussions}

\subsection{Physical properties}

A series of $\left(\mathrm{Ge}_{15} \mathrm{Ga}_{10} \mathrm{Te}_{75}\right)_{100-\mathrm{x}}(\mathrm{CsBr})_{\mathrm{x}}(\mathrm{x}=0,5,10,15,20,25,35,45,55,65,75,85)$ glasses were prepared. These glasses are completely opaque and black in the visible region, and the physical parameters of these glasses are listed in Table 1 . The densities of these glasses gradually decreased with increasing $\mathrm{CsBr}$ content because the glass density is generally determined by the elemental relative atomic mass. The relative molecular mass of $\mathrm{CsBr}$ was smaller than those of $\mathrm{GeTe}_{4}$ and $\mathrm{GaTe}_{3}$. The recruitment and increase of $\mathrm{CsBr}$ resulted in reduced $\mathrm{GeTe}_{4}$ and $\mathrm{GaTe}_{3}$ contents. Consequently, the densities of these glasses gradually decreased, and the average molar volume increased. The average molar volume of the glass sample can be achieved using Formula (1).

$$
V_{m}=\frac{\sum_{i} M_{i}}{\rho},
$$

where $M_{i}$ is the molar mass of glass sample $\left(M_{i}=A_{i} B_{i}, A_{i}\right.$, molar concentration; $B_{i}$, molecular weight of glass composition; $\rho$, density of glass samples).

Table 1 Physical and thermal parameters of $\left(\mathrm{Ge}_{15} \mathrm{Ga}_{10} \mathrm{Te}_{75}\right)_{100-\mathrm{x}}(\mathrm{CsBr})_{\mathrm{x}}$ glass samples

\begin{tabular}{|c|c|c|c|c|c|c|c|c|}
\hline $\begin{array}{c}\mathrm{x} \\
(\text { at. \%) }\end{array}$ & $\begin{array}{l}\rho \\
\left(\mathrm{g} \cdot \mathrm{cm}^{-3}\right)\end{array}$ & $\begin{array}{l}\mathbf{V}_{\mathrm{m}} \\
\left(\mathbf{m}^{3} \cdot \mathbf{m o l}^{-1}\right)\end{array}$ & $\begin{array}{l}\mathrm{Tg} \\
\left({ }^{\circ} \mathrm{C}\right)\end{array}$ & $\begin{array}{l}\mathrm{Tx} \\
\left({ }^{\circ} \mathrm{C}\right)\end{array}$ & $\begin{array}{r}\Delta \mathrm{T} \\
\left({ }^{\circ} \mathrm{C}\right)\end{array}$ & $\begin{array}{l}\text { Direct-E } \text { Ept }^{\prime} \\
(\mathbf{e V})\end{array}$ & $\begin{array}{l}\text { Indirect-E } \mathrm{E}_{\mathrm{op}} / \\
(\mathrm{eV})\end{array}$ & $\begin{array}{l}\text { Cut-off } \\
\lambda(\mathbf{n m})\end{array}$ \\
\hline 0 & 5.735 & 19.869 & 172 & 284 & 112 & 0.654 & 0.656 & 1789 \\
\hline 5 & 5.667 & 20.982 & 171 & 285 & 114 & 0.659 & 0.659 & 1847 \\
\hline 15 & 5.658 & 22.766 & 168 & 284 & 116 & 0.673 & 0.673 & 1816 \\
\hline 25 & 5.555 & 24.971 & 173 & 286 & 113 & 0.702 & 0.699 & 1796 \\
\hline 35 & 5.549 & 26.783 & 172 & 291 & 119 & 0.695 & 0.695 & 1718 \\
\hline 45 & 5.459 & 29.039 & 169 & 283 & 114 & 0.677 & 0.676 & 1739 \\
\hline 55 & 5.437 & 30.978 & 175 & 281 & 106 & 0.658 & 0.671 & 1744 \\
\hline 65 & 5.412 & 32.951 & 175 & 280 & 105 & 0.671 & 0.669 & 1766 \\
\hline 75 & 5.399 & 34.865 & 177 & 278 & 101 & 0.678 & 0.675 & 1830 \\
\hline 85 & 5.331 & 37.168 & 179 & 279 & 100 & 0.639 & 0.617 & 1860 \\
\hline
\end{tabular}

\subsection{XRD analysis}

XRD was conducted to verify the amorphous state of the samples. The XRD patterns of $\left(\mathrm{Ge}_{15} \mathrm{Ga}_{10} \mathrm{Te}_{75}\right)_{100-\mathrm{x}}(\mathrm{CsBr})_{\mathrm{x}}$ glass samples are presented in Fig. 1. The peak shapes in these diffraction curves exhibited dispersion and width. The XRD results indicated that these glass samples possessed an amorphous state. $\mathrm{Ge}_{15} \mathrm{Ga}_{10} \mathrm{Te}_{75}$ glass could remarkably dissolve as much as 


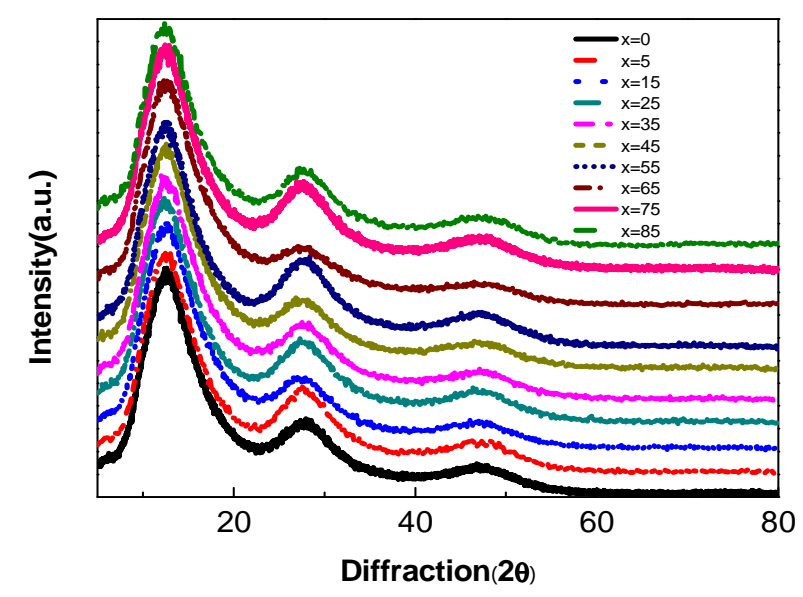

\subsection{Thermal properties}

Fig. 1 XRD patterns of powdered glass samples

Thermal properties of glass samples are an important aspect in evaluating a glass sample. The thermal characteristics of glass samples were tested with DSC instrument. DSC curves are all shown in Fig. 2. Two important parameters of glasses, namely, Tg and Tx, can be obtained with the curves. $\mathrm{Tg}$ is the glass transition temperature, and $\mathrm{Tx}$ is the glass onset crystallization temperature. Parameter $\Delta \mathrm{T}$ (the difference between $\mathrm{Tx}$ and $\mathrm{Tg}$ ) can be also obtained and used to estimate glass-forming ability and thermal stability. Stronger glass-forming ability and thermal stability indicates better anti-crystallization. The specific numerical temperatures $\mathrm{Tg}$ and $\mathrm{Tx}$ are also presented in Table 1 . The lowest $\Delta \mathrm{T}$ is $100{ }^{\circ} \mathrm{C}$, and the highest $\Delta \mathrm{T}$ is $119{ }^{\circ} \mathrm{C}$, which corresponded to the $\left(\mathrm{Ge}_{15} \mathrm{Ga}_{10} \mathrm{Te}_{75}\right)_{65}(\mathrm{CsBr})_{35}$ glass sample. In contrast to the $\Delta \mathrm{T}$ of $\mathrm{Ge}_{15} \mathrm{Ga}_{10} \mathrm{Te}_{75}$ glass sample, the $\Delta \mathrm{T}$ of $\left(\mathrm{Ge}_{15} \mathrm{Ga}_{10} \mathrm{Te}_{75}\right)_{65}(\mathrm{CsBr})_{35}$ glass was increased by $7{ }^{\circ} \mathrm{C}$. This finding proves that the proper content of alkali-halide $\mathrm{CsBr}$ added to the $\mathrm{Ge}_{15} \mathrm{Ga}_{10} \mathrm{Te}_{75}$ glass could improve glass stability when the content was lower than 35 at.\%. This result is attributed to the glass network structure, which was changed and improved by introducing halogen $\mathrm{Br}$ atoms. When the glass network was broken, the bromine atom could trap electrons of Te and form covalent bonds. Thus, a decreasing tendency of Te microcrystal formation occurred. Consequently, the stability of this glass against crystallization is ameliorated. However, increased $\mathrm{CsBr}$ content (>35 at.\%) could destroy the glass network because of excess terminal halogen. 


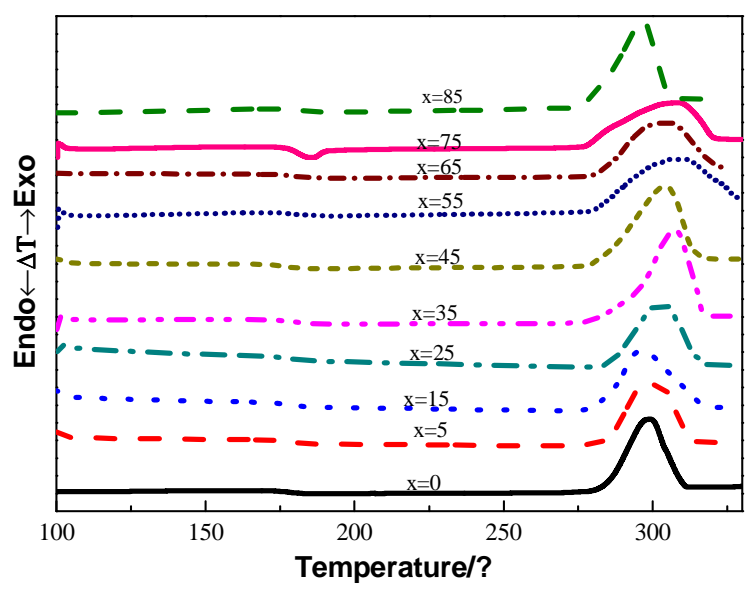

Fig. 2 DSC curves of Ge-Ga-Te-CsBr glass samples

\subsection{Raman spectra analysis}

The Raman spectra of the glasses are shown in Fig. 3, where four main vibration bands can be found. Three strong bands can be separately observed at 63,126 , and $159 \mathrm{~cm}^{-1}$, and a very weak band was located at $217 \mathrm{~cm}^{-1}$. The first and second bands could be attributed to the vibrations of Ge-Te bonds [13-15]. The peak at $159 \mathrm{~cm}^{-1}$ was ascribed to Te-Te bonds [11]. Moreover, the weak band at $217 \mathrm{~cm}^{-1}$ was caused by Ge-Ge bonds [16]. Some subtle changes occurred at the Te-Te peak, which was located at $159 \mathrm{~cm}^{-1}$. The increase of $\mathrm{CsBr}$ content resulted in gradual withdrawal of vibration intensity of Te-Te bonds from $x=5$ to $x=35$. However, when $\mathrm{x}$ was above 35 , the vibration intensity of Te-Te bonds gradually enhanced. This phenomenon occurred probably because the glass network structure was partly destroyed by $\mathrm{CsBr}$. In general, with the high electronegativity of $\mathrm{Br}^{-}$and low polarizability of $\mathrm{Cs}^{+}$doped into the $\mathrm{Ge}-\mathrm{Ga}-\mathrm{Te}$ glass, $\mathrm{GaTe}_{3}$ triangle and $\mathrm{GeTe}_{4}$ tetrahedra, which are the main structural units of glass network, were partly destroyed, particularly Te-Te chains. Bromine atom, as a network terminator, is considered to split the Te-Te chains. Thus, the Te-Te bonds reduced, and the terminal bonds $\mathrm{Ge}-\mathrm{Te}-\mathrm{Br}$ and $\mathrm{Ga}-\mathrm{Te}-\mathrm{Br}$ eventually formed. Therefore, the vibration band at $159 \mathrm{~cm}^{-1}$ gradually weakened. When $\mathrm{CsBr}$ content exceeded 45 at.\%, many dissociative Te atoms or Te atoms, which were under full valence state, may appear in the glass network. These Te atoms eventually combined together because of their strong metallic property, and the peak intensity at $159 \mathrm{~cm}^{-1}$ gradually strengthened. 


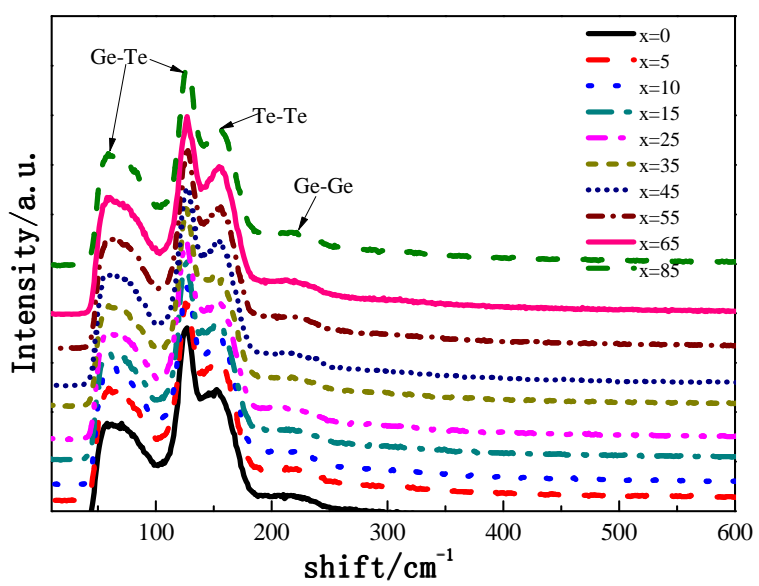

Fig. 3 Raman spectra of glass samples

\subsection{Near-infrared absorption spectra and optical band gap}

Near-infrared absorption spectra are shown in Fig. 4. When CsBr content increased from 5 at.\% to 35 at.\%, the absorption cut-off edge moved to short wavelength, which means that blue shift occurred. However, the absorption cut-off edge turned to long wavelength when $\mathrm{x}$ was above 35, which indicates that red shift occurred. Lastly, the shortest near-infrared cut-off wavelength was approximately $1718 \mathrm{~nm}$. This phenomenon existed as a result of the structure of $\mathrm{Ge}_{15} \mathrm{Ga}_{10} \mathrm{Te}_{75}$ glass, which was destroyed by the amount of $\mathrm{CsBr}$ content codoped. As shown in Fig. 3, the Te-Te bond intensity weakened when $\mathrm{x}$ was between 5 and 35 . Thus, glass formality and stability were improved. This phenomenon may explain the blue shift of absorption cut-off edge at short wavelength. The red shift of absorption cut-off edge may be ascribed to the increase of the Te-Te bond intensity.

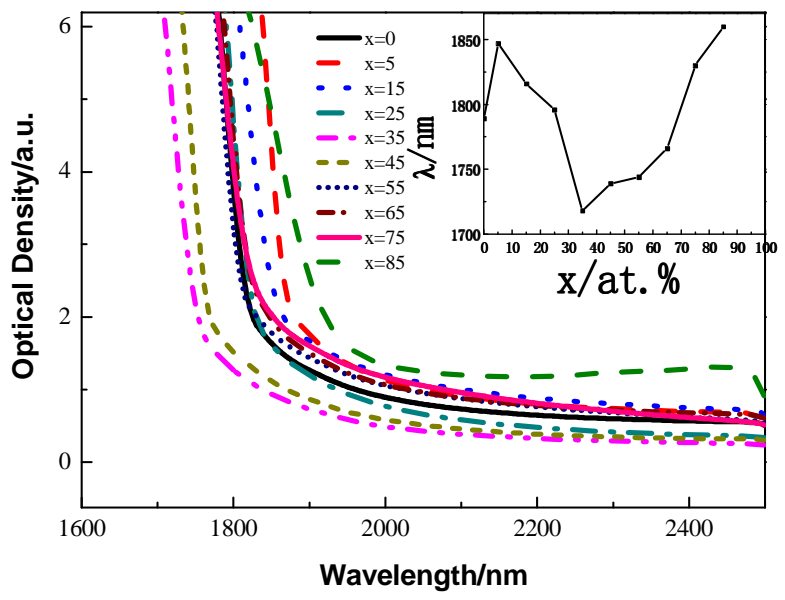

Fig. 4 Vis-IR absorption spectra of glass samples (relationships between cut-off edge wavelength and $\mathrm{CsBr}$ content are shown in the inset image)

The function relationship between absorption coefficient, $\alpha(\omega)$, and photon energy, $\hbar \omega$, of chalcogenide glass is given by Tauc equation [17]:

$$
\alpha(\omega) \cdot \hbar \omega=B\left(\hbar \omega-E_{\text {opt }}\right)^{\mathrm{m}}
$$

In the preceding equation, $\alpha$ is the absorption coefficient, which is determined as $\alpha=2.303 \mathrm{~A} / \mathrm{d}$ (A 
is the optical density of the testing glass sample, and $\mathrm{d}$ is the thickness of the glass sample), $\mathrm{E}_{\mathrm{opt}}$ is the optical band gap, $\hbar$ is Plank constant, $\omega$ is the incident light angular frequency, and $\mathrm{m}$ is a parameter that can determine the transition type of absorption edge. For amorphous glass materials, the direct and indirect allowed transitions correspond to $m=1 / 2$ and $m=2$, respectively. $B$ is a constant about local state in the band gap. It can be calculated with the following equation:

$$
B=\frac{(4 \pi c) \sigma_{0}}{n_{0} \Delta E}
$$

In Eq. (3), $\mathrm{c}$ is the light speed in vacuum, $\sigma_{0}$ is the electrical conductivity of absolute zero, $\mathrm{n}_{0}$ is the static refractive index, and $\Delta \mathrm{E}$ is the local state tail width. Figs. 5 and 6 correspond to the direct and indirect band gaps, respectively. The largest value of direct band gap is $0.702 \mathrm{eV}$, whereas the smallest value of indirect band gap is $0.617 \mathrm{eV}$. The band gap values of all the glass samples are listed in Table 1.

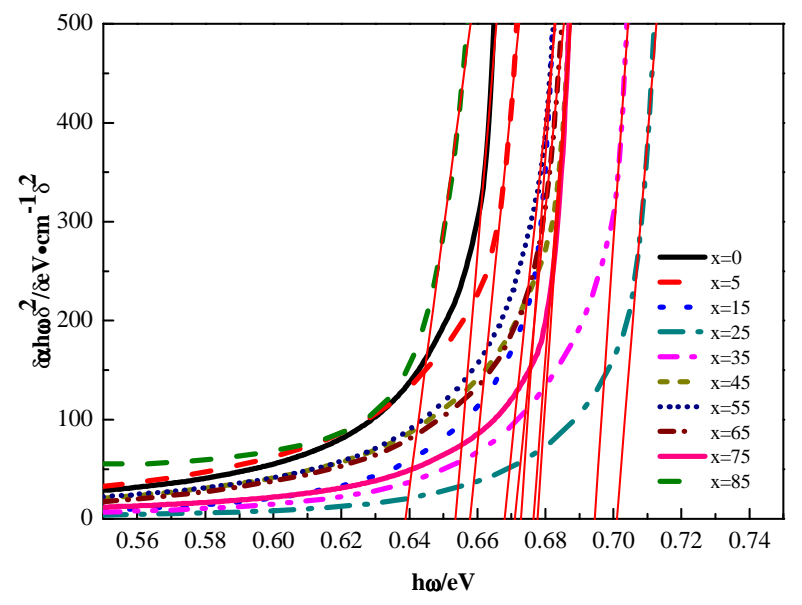

Fig. 5 Relationship between $(\alpha \bullet \hbar \omega)^{2}$ and $\hbar \omega$ for glass samples

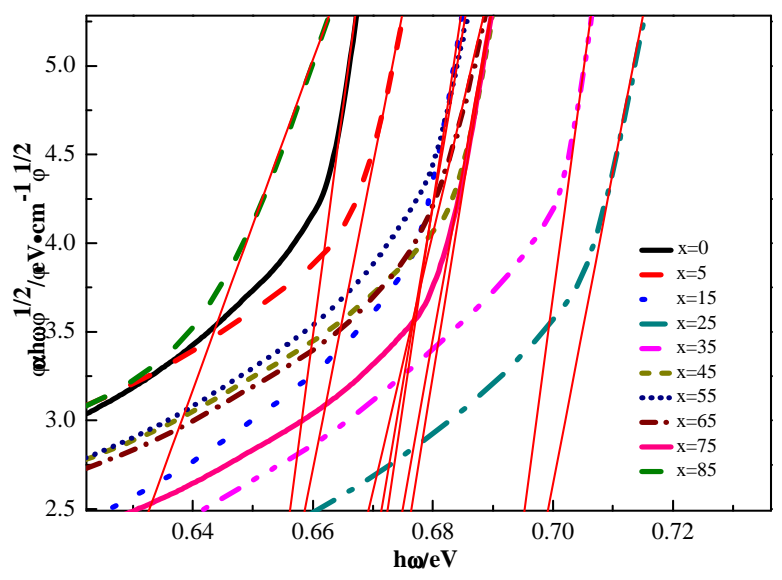

Fig. 6 Relationship between $(\alpha \bullet \hbar \omega)^{1 / 2}$ and $\hbar \omega$ for glass samples

\subsection{Infrared transmission spectra analysis}

The infrared transmitting spectra of the glass samples are shown in Fig. 7. The highest transmission was up to 53\% (close to the theoretical limitation), without purification for the $\left(\mathrm{Ge}_{15} \mathrm{Ga}_{10} \mathrm{Te}_{75}\right)_{80}(\mathrm{CsBr})_{20}$ glass sample. All glass samples had a wide infrared transmitting window, 
and the infrared cut-off wavelength could reach up to $25 \mu \mathrm{m}$. However, when the wavelength was more than $20 \mu \mathrm{m}$, the transmittance of the glass samples sharply reduced. This result can be ascribed to the multiphonon absorption produced by the Ge-Te bond vibration [5]. Some other absorption peaks can also be observed in Fig. 7. The peak at $9.9 \mu \mathrm{m}$ resulted from $\mathrm{Si}-\mathrm{O}$ covalent bond vibration. The peak at 15-20 $\mu \mathrm{m}$ can be ascribed to the presence of some oxygen contamination, such as $\mathrm{Ge}-\mathrm{O}$ or $\mathrm{Ga}-\mathrm{O}$ bond vibrations $[18,19]$. The intensity of this peak depends on the purity of raw materials. The $\left(\mathrm{Ge}_{15} \mathrm{Ga}_{10} \mathrm{Te}_{75}\right)_{80}(\mathrm{CsBr})_{20}$ glass sample that possessed highest transmittance was chosen for the next purification experiment to eliminate glass absorption peaks. The first method was distilling raw Te, and the purified Te was then transferred to another quartz ampoule that contained $\mathrm{Ge}, \mathrm{Ga}$, and $\mathrm{CsBr}$ raw materials. Another method is codoping $500 \mathrm{ppm}$ Mg into a raw Te-containing ampoule. Te was then distilled with the same method mentioned previously. The succeeding steps were the same as those in the traditional melt-quenching methods. The transmission spectra of $\left(\mathrm{Ge}_{15} \mathrm{Ga}_{10} \mathrm{Te}_{75}\right)_{80}(\mathrm{CsBr})_{20}$ glasses, which were obtained by the preceding two methods, are shown in Fig. 8. The intensity of absorption peak from $15 \mu \mathrm{m}$ to $20 \mu \mathrm{m}$ decreased when the first method was adopted to purify the glass. However, this method cannot thoroughly remove the absorption peaks. For the second purification method, the absorption peaks could be completely eliminated, and the transmittance of this glass can reach up to $54 \%$.

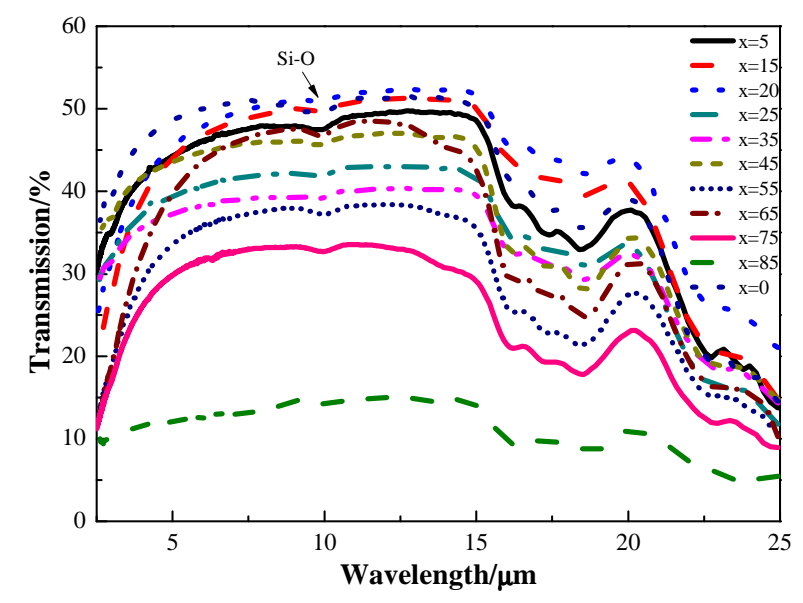

Fig. 7 Infrared transmission spectra of glass samples $\left[\left(\mathrm{Ge}_{15} \mathrm{Ga}_{10} \mathrm{Te}_{75}\right)_{100-\mathrm{x}}(\mathrm{CsBr})_{\mathrm{x}}\right]$ 


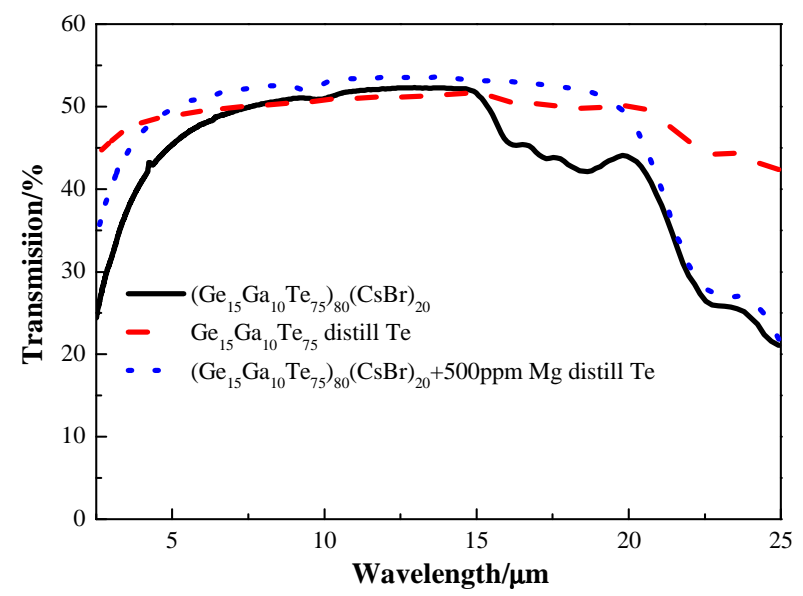

Fig. 8 Infrared spectra of $\left(\mathrm{Ge}_{15} \mathrm{Ga}_{10} \mathrm{Te}_{75}\right)_{80}(\mathrm{CsBr})_{20}$ glasses

\section{Conclusion}

A novel series of $\mathrm{Ge}-\mathrm{Ga}-\mathrm{Te}-\mathrm{CsBr}$ glasses were prepared via a traditional vacuum melting and quenching method. The thermal, physical, and optical properties of these glasses were investigated in detail. All glass samples exhibited good thermal and physical properties. The $\left(\mathrm{Ge}_{15} \mathrm{Ga}_{10} \mathrm{Te}_{75}\right)_{65}(\mathrm{CsBr})_{35}$ glass was superior to other glass samples. The $\Delta \mathrm{T}$ of this glass was 119 ${ }^{\circ} \mathrm{C}$ and was higher than that of $\mathrm{Ge}_{15} \mathrm{Ga}_{10} \mathrm{Te}_{75}$ glass, which is only $112{ }^{\circ} \mathrm{C}$. The solubility of alkali-halide $\mathrm{CsBr}$ in $\mathrm{Ge}-\mathrm{Ga}-\mathrm{Te}$ glass can reach as much as 85 at.\%, which can be distinguished as a new kind of halide-based glass. The infrared transmittance of all the glass samples showed wide optical windows, which ranged from $1.7 \mu \mathrm{m}$ to $25 \mu \mathrm{m}$. These excellent properties make $\mathrm{Ge}-\mathrm{Ga}-\mathrm{Te}-\mathrm{CsBr}$ glasses potential materials for ultrawide spectrum infrared optical applications.

\section{Acknowledgments}

This work was financially supported by the Natural Science Foundation of China (Grant Nos. 61435009, 61177087, and 61377099), National Program on Key Basic Research Project (973 Program) (Grant No. 2012CB722703), International Science \& Technology Cooperation Program of China (Grant No. 2011DFA12040), Scientific Research Fund of Zhejiang Provincial Education Department (R1101263), Natural Science Foundation of Ningbo (Grant No. 2013A610118), Teaching and Research Award Program for Outstanding Young Teachers in Higher Education Institutions of MOE, P.R.C. Ningbo Optoelectronic Materials and Devices Creative Team (2009B21007), and Scientific Research Foundation of Graduate School of Ningbo University. This work was also sponsored by K. C. Wong Magna Fund of Ningbo University and the Outstanding (Postgraduate) Dissertation Growth Foundation of Ningbo University (Grant No. PY2014014). 


\section{References}

[1] C. Quémard, F. Smektala, V. Couderc, J. Phys. Chem. Solids 62 (2001) 1435-1440.

[2] B. Bureau, X.H. Zhang, F. Smektala, J. Non-Cryst. Solids 345 (2004) 276-283.

[3] A.A. Wilhelm, C. Boussard - Pledel, Q. Coulombier, Adv. Mater. 19 (2007) 3796-3800.

[4] X.H. Zhang, G. Fonteneau, J. Lucas J. Non-Cryst. Solids 104 (1988) 38-44.

[5] S. Danto, P. Houizot, C. Boussard - Pledel, Adv. Funct. Mater. 16 (2006) 1847-1852.

[6] X.B. Yu, X. Zhao, C.H. Li, Journal of Dalian Polytechnic University 27 (2008) 155-157.

[7] G.X. Wang, Q.H. Nie, X.S. Wang, J. Appl. Phys. 110 (2011) 043536.

[8] S. Maurugeon, B. Bureau, C. Boussard-Plédel, J. Non-Cryst. Solids 355 (2009) 2074-2078.

[9] W.D. Chen, F. Cazier, F. Tittel, Appl. Opt. 39 (2000) 6238-6242.

[10] L. Aldon, P. Lippens, J. Olivier-Fourcade, Chalgogenide Letters 7 (2010) 187-196.

[11] X.S. Wang, Q.H. Nie, G.X. Wang, Spectrochimica Acta Part A 86 (2012) 586-589.

[12] H.J. Xu, X.S. Wang, Q.H. Nie, J. Non-Cryst. Solids 383 (2014) 212-215.

[13] A.V. Kolobov, P. Fons, J. Tominaga, J. Phys.: Condens. Matter 16 (2004) S5103.

[14] S. Sen, E.L. Gjersing, B.G. Aitken J. Non-Cryst. Solids 356 (2010) 2083-2088.

[15] K.S. Andrikopoulos, S.N. Yannopoulos, A.V. Kolobov, J. Phys. Chem. Solids 68 (2007) 1074-1078.

[16] T. Fukunaga, Y. Tanaka, K. Murase Solid State Commun. 42 (1982) 513-516.

[17] J. Tauc, Amorphous and liquid semiconductors. (Plenum Publishing Corporation, 1974).

[18] Y.J. He, X.S. Wang, Q.H. Nie, Infrared Physics \& Technology 60 (2013) 129-133.

[19] S.Q. Zhang, X.H. Zhang, M. Barillot, Opt. Mater. 32 (2010) 1055-1059. 